\section{DESENVOLVIMENTO DESIGUAL, “QUESTÃO REGIONAL” E TENDÊNCIAS CONTEMPORÂNEAS}

\author{
DESARROLLO DESIGUAL, “CUESTIÓN REGIONAL” \\ Y TENDENCIAS CONTEMPORÁNEAS
}

\section{UNEQUAL DEVELOPMENT, "REGIONAL ISSUE" AND CONTEMPORARY TRENDS}

Evelyne Medeiros PEREIRA ${ }^{I}$

\section{Resumo}

O contexto contemporâneo é constituído na permanente dialética entre mudanças e continuidades, particularmente no âmbito das desigualdades regionais, fazendo ainda com que regiōes como o Nordeste brasileiro tenha uma elevada taxa de analfabetismo e um reduzido índice de desenvolvimento humano, apesar da melhoria nas condiçóes de vida e trabalho dos setores mais subalternizados durante a última década. $\mathrm{O}$ presente artigo é fruto do esforço de uma breve caracterização e problematização da "questão regional" no Brasil a partir da região Nordeste no contexto dos anos 2000. Para tanto, a contextualização dessa questão no padrão de desenvolvimento capitalista, atentando para algumas de suas tendências, como a lei do desenvolvimento desigual e combinado, foi um passo fundamental, demandando o diálogo com a realidade empírica através da pesquisa bibliográfica e documental, além do levantamento de dados primários e secundários referente

\footnotetext{
${ }^{1}$ Doutoranda em Serviço Social na Universidade Federal do Rio de Janeiro (UFRJ). Docente do quadro efetivo do Curso de Serviço Social do Instituto Federal de Educação, Ciência e Tecnologia do Ceará (IFCE), campus Iguatu. Líder do Núcleo de Pesquisa Educação, Políticas Sociais e Serviço Social. Tem experiência na área de Serviço Social com ênfase em Movimento Sociais, Questão Agrária, Educação e Economia Política. Email: evelyne.mp2913@gmail.com.
}

\section{.}


ao período priorizado. Ressaltamos a necessidade da conexão entre a análise da realidade regional e o movimento mundial articulador de territórios que perpetua o "amalgama de formas arcaicas com as mais modernas", em especial nas formaçóes sociais dependentes como a brasileira.

Palavras-chave: Desenvolvimento desigual. Questão Regional. Nordeste brasileiro.

\section{Resumen}

El contexto contemporáneo es constituido en la permanente dialéctica entre cambios y continuidades, particularmente en el ámbito de las desigualdades regionales, haciendo incluso con que las regiones del Nordeste brasilero tengan una elevada taza de analfabetismo y un reducido indice de desarrollo humano, a pesar de la mejoría de las condiciones de vida y de trabajo de los sectores más subalternizados durante la última década. El presente artículo es fruto del esfuerzo de una breve caracterización y problematización de la "cuestión regional" en Brasil a partir de la región Nordeste en el contexto de los años 2000. Para esto, la contextualización de esa cuestión en el padrón de desarrollo capitalista, atentando para algunas de sus tendencias, como la ley de desarrollo desigual y combinado, fue un paso fundamental, demandando dialogo con la realidad empirica a través de la investigación bibliográfica y documental, mas alla del levantamiento de datos primarios y segundarios referentes al periodo priorizado. Resaltamos la necesidad de la conexión entre el análisis de la realidad regionaly el movimiento mundial articulador de territorios que perpetúa la "amalgama de formas arcaicas con las más modernas", en especial en las formaciones sociales dependientes como la brasilera.

Palabras clave: Desarrollo desigual. Cuestión Regional. Nordeste brasilero. 


\section{Abstract:}

The contemporary context is constituted by a permanent dialectic between changes and continuities, particularly in the context of regional inequalities, making regions such as the Brazilian Northeast have a high rate of illiteracy and a low rate of human development, despite the improvement in living conditions and work of the most subordinated sectors during the last decade. The present article is the result of a brief characterization and problematization of the "regional issue" in Brazil from the Northeast region in the context of the years 2000. For this, the contextualization of this issue in the pattern of capitalist development, taking into account some of its tendencies, as the unequal and combined development law, was a fundamental step, demanding dialogue with empirical reality through bibliographical and documentary research, as well as the collection of primary and secondary data regarding the prioritized period. We emphasize the need for the connection between the analysis of regional reality and the world movement that articulates territories that perpetuates the "amalgamation of archaic and modern forms", especially in dependent social formations such as Brazil.

KEYWORDS: Unequal development. Regional Issue. Brazilian Northeast.

\section{INTRODUÇÃO}

Sabemos que as desigualdades regionais compóem a dinâmica do desenvolvimento capitalista, apresentando uma tônica particular nas formaçóes sociais dependentes, como é o caso da sociedade brasileira, devido à forma específica de integração ao mercado mundial. Isso não quer dizer que tais desigualdades, ora mais graves, ora mais tênues, não componham outros diversos contextos, inclusive de países "centrais", como é o caso daqueles do Sul da Europa que se inserem no bloco europeu de forma periférica. Esse fenômeno foi alvo de diversas elaboraçóes, como as de Antônio Gramsci (2002), que encontrou no Risorgimento italiano cenário propício para analisar a questão meridional na Itália moderna.

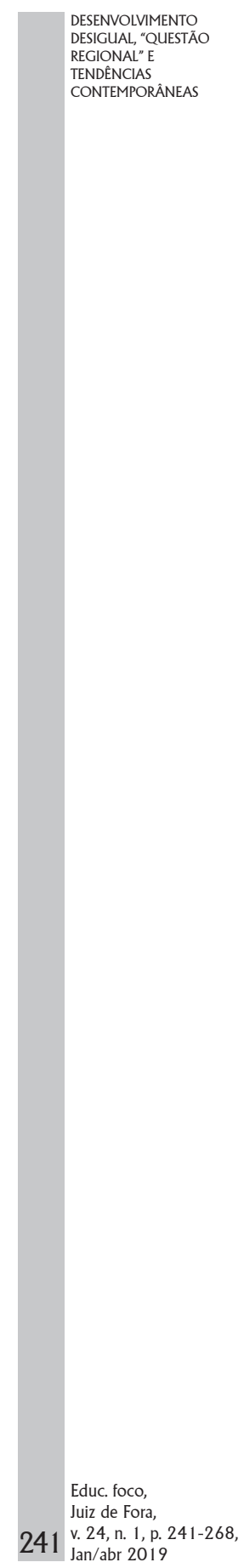


Essas realidades demonstram a veracidade da lei do desenvolvimento desigual e combinado, revelando o caráter integrador e ao mesmo tempo desintegrador de regióes no capitalismo, que, para Leon Trotsky (1977, p. 25), viabiliza uma "aproximação das diversas etapas, combinação das fases diferenciadas, amálgama das formas arcaicas com as mais modernas". Daí o entendimento de que não há etapas bem definidas de desenvolvimento pelas quais cada formação social deva passar, inevitavelmente ou predestinadamente. Essa constatação contribuiu decisivamente para compreender, por exemplo, o "por que" foi viável na história da Rússia agrária uma revolução popular socialista, além da existência de formas de sociedade tão distintas sob o mesmo modo de produção. Da Rússia para o Brasil, o entendimento de como nossa sociedade tornou-se burguesa sem vivenciar, de fato, um processo de ruptura com o latifúndio e seus antigos representantes é, a nosso ver, pressuposto central para o estudo sobre os fundamentos das desigualdades regionais enquanto fenômeno moderno.

O contexto contemporâneo nos mostra que, diante do rentismo e da financeirização como forma prioritária de valorização do capital, a busca de superar as fronteiras de tempo e espaço tornou-se uma necessidade, porém, esse mesmo desenvolvimento acaba estabelecendo outras tantas barreiras territoriais e diferenciaçôes regionais. É uma mundialização que também se regionaliza. Fruto desse processo ocorre o adensamento da questão social na sua dimensão regional, expressa pela intensificação da divisão internacional do trabalho, da exploração por intermédio da reestruturação produtiva e dos diversos conflitos de base territorial refletidos na violenta onda migratória cada vez mais pulsante nos dias de hoje.

No Brasil, compreendemos a região Nordeste como destaque na divisão inter-regional do trabalho, sofrendo com maior tônica os reflexos da concentração de riqueza e renda no país. Os desdobramentos econômicos e políticos desse 
processo constituíram uma narrativa dominante e elitista de "região-problema" que predomina até hoje, muito embora com aspectos dissonantes, presentes no último ciclo de desenvolvimento no país.

Diante de tais inquietações, este artigo objetiva apresentar brevemente alguns aspectos que caracterizam a realidade brasileira dos anos 2000, atentando para os desdobramentos na (re)configuração da questão regional a partir da região Nordeste. Para tanto, é preciso recorrer à pesquisa bibliográfica e documental, construindo um diálogo com a realidade empírica mediante informaçóes coletadas, com explicitação de dados primários e secundários referente ao período priorizado na pesquisa. Dentre as fontes, estáo servindo como subsídio as pesquisas e os censos publicados pelo Instituto de Pesquisa Econômica e Aplicada (IPEA) e o Instituto Brasileiro de Geografia e Estatística (IBGE). Isto além dos documentos como a Política Nacional de Desenvolvimento Regional (PNDR) e os Planos Plurianuais dos governos brasileiros nesse período.

A exposição encontra-se organizada em dois principais eixos. O primeiro contém uma rápida identificação do Nordeste e da questão regional no Brasil hoje; o segundo apresenta algumas problematizaçóes e apontamentos sobre os fundamentos dessa realidade, ancorados nas particularidades constitutivas do padrão capitalista de desenvolvimento.

\section{O NORDESTE HOJE E A “QUESTÃo REgIONAL” BRASILEIRA}

É certo que as expressôes atuais da realidade nordestina, especialmente da última década, tais como o aumento da expectativa devidae a diminuição da pobreza absoluta, sinalizam inflexóes da questão social na região. Isto muito propagandeado como resultado de uma política de inclusão social, com maior peso para o desenvolvimento regional, durante os governos capitaneados pelo Partido dos Trabalhadores (2003-2015), que teria promovido maior crescimento econômico em regióes

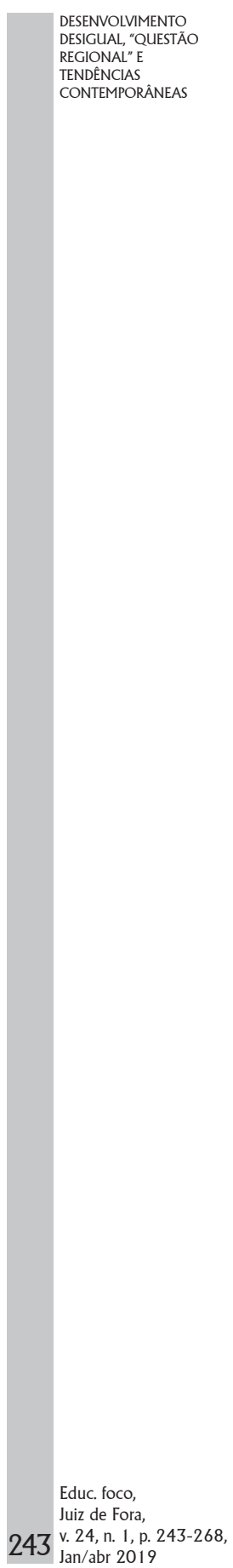


historicamente mais pauperizadas e com menores índices de desenvolvimento humano do país.

Essa constatação é possível ser observada na própria realidade, não apenas através dos indicadores sociais e econômicos desse período que demonstram uma efetiva melhoria das condições de vida dos trabalhadores com a ampliação de postos de trabalho, de industrialização (inclusive na agricultura), do acesso à renda, ao consumo e a políticas sociais como a educação e assistência, como também através dos resultados na política institucional, fazendo da região uma importante base eleitoral desses governos. Quais os fatores que permitiram tais inflexóes na região no último ciclo de desenvolvimento? As respostas para tais questôes certamente estáo muito além da simples vontade política.

De fato, ao se observar os números e os documentos oficiais, particularmente os planos plurianuais governamentais, é possível identificar algumas diferenciaçóes em relação à ortodoxia neoliberal em curso no país durante a década de 1990. A regiāo Nordeste efetivamente esteve entre as prioridades dadas por parte de instituiçóes estatais via "políticas de desenvolvimento", a exemplo do Banco Nacional de Desenvolvimento Econômico e Social (BNDES), através do financiamento de grandes projetos infraestruturais e industriais, como a Transposição do Rio São Francisco, os Complexos Portuários e Siderúrgicos, os Polos Industriais e a Transnordestina (estrada de ferro entre os estados de Pernambuco, Piauí e Ceará), além de programas como o Programa Bolsa Família, o Minha Casa Minha Vida e o Luz Para Todos, que priorizaram o atendimento de quem esteve à margem do trabalho formal ou mesmo aqueles que não foram incorporados pelo mercado. Tudo isso sob a ideia de "fazer crescer o bolo para depois reparti-lo”.

De acordo com a Empresa Brasil de Comunicação, até 2014, "a economia da região mais pobre do Brasil crescia num ritmo muito superior a média nacional. Das cinco regióes brasileiras, o Nordeste foi a que gerou mais empregos formais 
nos últimos anos”. (IBGE, 2014). Já as pesquisas divulgadas pelo IBGE, em 2012, chegaram a revelar que ocorreu uma inversão no histórico movimento de migração entre as regióes. Em vez da corrida para o Sudeste que marcou as décadas de 1960 a 1980, a tendência era de deslocamentos entre municípios de um mesmo estado e queda acentuada nas migraçóes entre regiôes, tendo como principais fatores para a diminuição no número de migrantes a saturação das metrópoles e a melhor distribuição da oferta de emprego.

Sobre isso, o economista Márcio Pochmann (2014) refere-se à primeira década do século 21 no Brasil como sendo aquela que, de certa forma, viabilizou o "protagonismo de regióes que eram vistas como atrasadas como é o caso da região Nordeste, Norte e Centro-Oeste, que são regióes que absorveram indústrias pela força do movimento de deslocamento de indústrias", impulsionando a constituição de uma estrutura produtiva antes inexistente ou, pelo menos, bem diferente do que havia originalmente. Portanto, "o Norte, Nordeste e Centro-Oeste foram regiôes que mais cresceram economicamente", o que, por outro lado, não tem impedido a gestação de novas elites regionais, muito pelo contrário.

Segundo a professora Tânia Bacelar (2013), "no período de 2003 a 2010 (...) houve também uma liderança da região Nordeste, junto à regiáo Norte, do crescimento do consumo ao longo dos anos 2000. Além disso, ressalta que a elevação real do salário-mínimo teve impacto mais forte na realidade nordestina, "onde $45 \%$ dos ocupados receberam até 1 saláriomínimo - bem acima da média nacional que era de 26\% (...) entre 2003 e 2009 o valor do rendimento médio das famílias" da referida região "cresceu $5,4 \%$ ao ano, quando a média brasileira foi de $3,5 \%$, e no Sudeste essa taxa foi de apenas 2,9\%".

Levando em consideração que as desigualdades regionais favorecem a divisão entre pobres e ricos territorialmente, como o Nordeste possui mais da metade da população muito pobre do país, captou 55\% dos recursos do Programa Bolsa

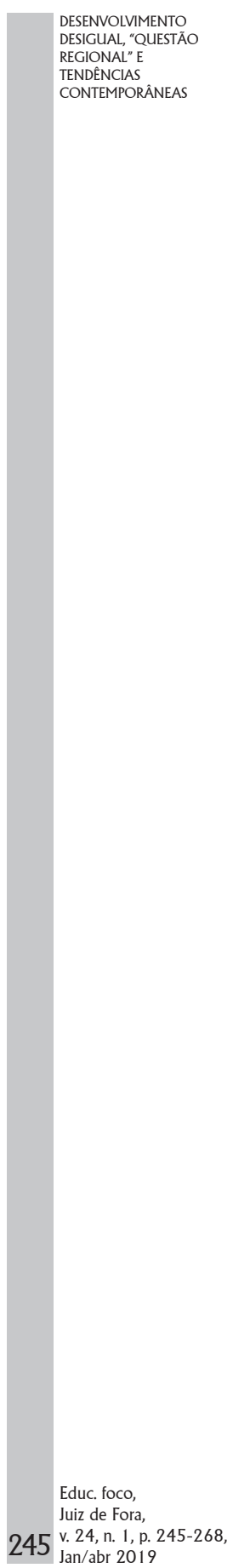


Família, "cargo-chefe" da Política de Assistência Social dos governos no referido período, o que influenciou diretamente tanto nas condiçóes de vida dessa parcela populacional como na dinâmica econômica e territorial do interior nordestino com a constituição das chamadas "cidades médias" (centros urbanos com população de 100 mil a 2 milhóes), dinamizando o comércio e gerando, assim, "nos pequenos municípios um impacto econômico num movimento virtuoso que estimula a crescer”. (ARAÚJO, 2013). Contudo, tal programa, além das diretivas da focalização e assistencialização, desenvolveu-se sob a lógica da indispensável intermediação dos bancos, revelando as contradições das políticas sociais que, "além de servirem ao capital por reduzirem o custo de reprodução da força de trabalho e atenuarem os conflitos de classe [...] servem, cada vez mais, à acumulação capitalista de modo direto" (BRETTAS, 2013, p. 202).

Ainda ressaltamos que algumas açôes, desenvolvidas na última década, vinculadas a outras políticas, a exemplo da educação profissional e superior, com uma tendência a expansão e a interiorização, adensaram impactos significativos na vida cultural, política e econômica desses territórios.

A elevação do PIB que, segundo Grabois (2014), quadruplicou de 2003 para 2013, com o destaque para algumas regióes como o Nordeste; o incentivo dado à descentralização territorial na implantação de polos industriais, a exemplo da indústria naval, "renascida na esteira do petróleo", concentrada no Rio de Janeiro, mas que teve presença significativa em estados como Ceará, Pernambuco, Alagoas e Bahia; o crescimento do número de trabalhadores da indústria, passando de 4 milhóes e 800 mil, em 2003, para quase 13 milhôes, em 2013, na indústria de transformação e de 2 milhôes para 6 de milhôes na construção civil no mesmo período; são aspectos que influenciaram na base de sustentação do projeto de desenvolvimento em curso até 2014.

Todavia, os dados também demonstram que ocorreu, simultaneamente, a perda de base industrial no Sul e Sudeste, 
"regióes hoje cada vez mais apegadas ao agronegócio, ao setor financeiro, aos serviços. Então isso fez com que essas regiôes náo tivessem um crescimento táo exitoso como observado nas regióes identificadas anteriormente como regiōes subdesenvolvidas, regiôes mais pobres". (POCHMANN, 2014).

Esse quadro incidiu sobre o aumento da expectativa de vida da populaçáo nordestina e a tendência positiva que apontavam diversos indicadores de elevaçáo da participação da região Nordeste no Produto Interno Bruto (PIB) nacional. O Nordeste do "atraso", da fome e da migraçáo tornou-se a região do "protagonismo", o Nordeste moderno, das oportunidades, da interiorização dos serviços, do regresso daqueles que um dia tiveram que tentar a vida longe, constituindo trajetórias de vida de inúmeros anônimos que inspiraram a arte popular de Luiz Gonzaga a Belchior.

Há realmente um novo desenho social e econômico da região?

Essas mudanças se deveram a quê?

O que há de herança e ruptura?

Acreditamos que para entender essa realidade é preciso desvendar um Nordeste profundo, em suas contradiçóes e heterogeneidades, porém, já que o "sertão é o mundo", segundo Antônio Cândido (2014), é preciso também transcendê-lo, ir para além da regiáo, dos discursos de desenvolvimento, das alianças e propostas políticas dos governos. Isso em busca de entender como essa região se (des)integra ao capitalismo; de identificar os "fios invisíveis" que constituem a dinâmica regional-universal no modo vigente de produção e reprodução da vida social, particularmente no período priorizado por nós, ano 2000. Esse caminho, náo pode ser feito sem revelar as ambiguidades e os paradoxos constitutivos dessa realidade, assim como não há possibilidade de entender as expressóes 
e formas de enfrentamento a questão social de outrora, a exemplo do cangaço ${ }^{2}$, por uma via de mão única.

Nesse sentido, é necessário perceber, antes de tudo, um "contrapeso" fundamental que, a nosso ver, viabilizou o crescimento econômico do Nordeste nos anos 2000 e seus consequentes impactos na questáo social: primeiro, a política de conciliação de classes vigente no referido período foi pautada e sustentada por um ganho maior de setores empresariais, inclusive do agronegócio. Assim, como lado mais pesado da mesma moeda, os governos em questáo, ao retomarem a política industrial, relegada pelo governo FHC, e reorientarem a atuação estatal, deixam clara a ausência de ruptura com o neoliberalismo, todavia, com maiores tensóes e medidas relativamente diferentes daquelas definidas nos governos anteriores; segundo, houve estagnação de outras regiôes; terceiro, é possível observar a ausência de significativas mudanças nas desigualdades sociais e concentração de renda. Sobre isso, de acordo com o Atlas da Exclusão Social no Brasil (2015), em 1980, o país era a $8^{\circ}$ economia do mundo e era o $3^{\circ}$ país mais desigual do mundo. Em 2015, foi para a $7^{\circ}$ economia do mundo, sendo o $17^{\circ}$ país mais desigual.

Como resultado desse processo, a melhoria nas condiçóes de vida sinaliza de modo cada vez mais latente o seu caráter relativo e temporário. As próprias taxas de crescimento náo têm sido estáveis, constantes, nem significativamente altas, especialmente nos últimos anos, o que, a nosso ver, revela os limites da política de conciliação de classes que foi bem-sucedida por um tempo. Isso tendo em vista que a dinâmica capitalista possibilita, dentro da dialética de expansão e estagnação entre as regióes, um período, mesmo que temporário, de ascensão econômica e de desdobramento de contratendências. Essas condiçôes incidiram na dinâmica migratória, na divisão regional do trabalho e, consequentemente, na questão social no Nordeste, o que não significa um peso menor das desigualdades

\footnotetext{
${ }^{2}$ Cf. livro Cangaceiros e Fanáticos, de Rui Facó (1963).
} 
regionais (tanto em âmbito nacional como internacional), pois, dentre outros fatores, não houve desconcentração no território brasileiro de riquezas socialmente produzidas.

Assim, junto às concepçóes ainda hegemônicas da realidade nordestina que, sob o viés homogeneizante, com o respaldo dos principais meios de comunicação, por um lado, (re) constroem a paisagem pitoresca do litoral turístico e reforçam a caricatura árida do sertanejo miserável e analfabeto; por outro, renovam o fenômeno do regionalismo "problemático e emblemático" que, em outro extremo, busca nos atributos regionais aspectos que possam hierarquicamente compor ou "tecer o nacional" e sua "essência"; emerge um novo desenho social e econômico da região em que o moderno empresariado nordestino vincula-se à estrutura de serviços que as políticas de desenvolvimento regional ajudaram a desenvolver na região. Para tanto, o BNDES teve papel fundamental. Este passou a investir, em 2007, o dobro que investia em 2000, priorizando, até 2009, programas e projetos de infraestrutura voltados para o Nordeste, já sinalizados por nós, além das isenções fiscais e da oferta de mão de obra mais barata em relação a outras regióes do país, atraindo setores industriais e da construção civil, nacionais e internacionais. Isto tendo em vista a margem salarial dos trabalhadores que vivem nos estados do Nordeste e ganham em torno de um salário-mínimo, quando essa média chega a triplicar em outras regióes do país, principalmente Sul e Sudeste. (IPEA, 2010).

Nesse quadro, "temos (...) novamente esboçado um modelo decisório de inversão de recursos públicos que utiliza o espectro dos 'pobres' para a montagem de engrenagens grandiosas de acumulaçáo de capital (...)” (DÓRIA, 2007, p. 289). Grupos empresariais como os bancos Itaú e Bradesco e as empreiteiras Odebrecht, Andrade Gutierrez e Camargo Correa, além daqueles que atuam mais diretamente no agronegócio, como a Suzano papel e celulose, antiga Aracruz Celulose, também ganharam bastante destaque. O BNDES, por exemplo, disponibilizou na última década por volta de um

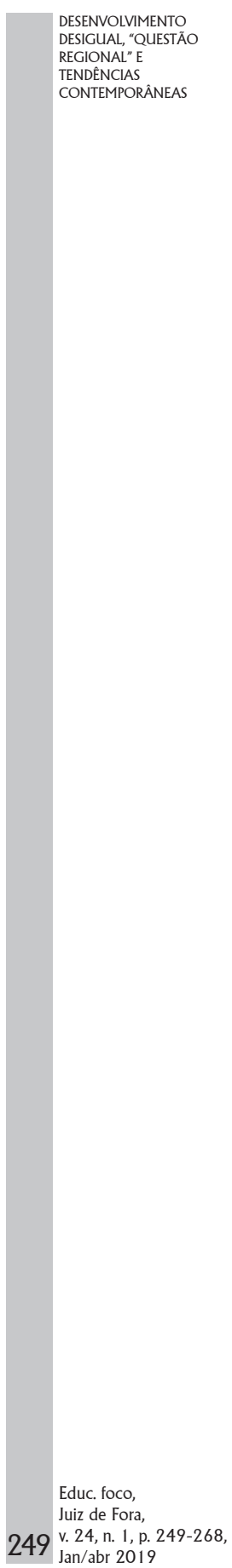


terço do total dos recursos "para somente dez grandes grupos econômicos privados em processo de concentração e fusão”. (POCHMANN, 2013, p. 152).

É importante observar as contradiçóes vivenciadas no cotidiano da vida de milhóes de trabalhadores que compóem um permanente e contínuo quadro de desigualdade regional que ainda faz do Nordeste um destaque em baixos Índices de Desenvolvimento Humano (IDH), elevados indicadores de analfabetismo, mortalidade infantil e pobreza, em geral. Em 2010, por exemplo, a "taxa de analfabetismo das pessoas de 10 anos ou mais para o país era de $9 \%$, mas a do Nordeste era de 17,6\%, enquanto a do Sul era de 4,7\%”. (ARAÚJO, 2013, p. 171).

Apesar de tudo, o recente crescimento econômico não altera no mesmo ritmo as condições de vida de milhares de pessoas que continuam atingidas pela exclusão e pobreza, em especial nas grandes áreas metropolitanas e no sertão semiárido (...) a distribuição de renda, de terras e de oportunidades continua desigual no Nordeste, e o baixo índice de Desenvolvimento Humano (IDH), ao lado da concentração espacial da indústria e das atividades econômicas de destaque, ainda é uma realidade. (PEREIRA JR, 2012, p. 225).

Esse quadro contribui para a permanente e considerável presença de emigrantes que ainda saem para outras regióes em busca de melhores condiçóes de vida, muito embora em um movimento menos ascendente que no século passado.

Para Pochmann (2013, p. 152), os estados mais ricos absorveram a "maior parte do fundo público comprometido com as transferências monetárias”, sendo incorporado pela regiáo Sudeste " $50 \%$ do total dos recursos anualmente comprometidos com as transferências previdenciárias e assistenciais da seguridade social". Esse quadro revela também a ausência de avanços substanciais em políticas sociais voltadas para o enfrentamento de tais desigualdades para além de açôes 
pontuais, como o Fundo Constitucional de Financiamento do Nordeste (FNE), criado ainda na década de 1980 e de cunho mais assistencial. Na verdade, a Política Nacional de Desenvolvimento Regional (PNDR), desenvolvida prioritariamente pelo Ministério da Integração Nacional nos últimos anos, não rompe com a herança neoliberal, o que facilita a reversão rápida dos ganhos e a reposição das disparidades socioregionais. Sobre isso, vejamos a seguinte avaliação:
Em termos históricos, após interrupção de no mínimo duas décadas e meia, a atenção pública ao problema do desenvolvimento regional foi retomada. A política nacional de desenvolvimento regional foi desenhada no programa de governo de Luiz Inácio Lula da Silva, aparecendo entre os grandes objetivos do Plano Plurianual de 20042007, bem como nos planos subsequentes. (...) Os textos desses documentos registram incômodo com as disparidades sociais e regionais do país, sinalizando compromisso em retomar políticas públicas (...) a exemplo daquelas políticas clássicas dos anos 1940/1960 da era nacionaldesenvolvimentista. (...) Os limites das proposiçóes do ministério começam na ação política concreta para lidar com os interesses das elites, mas também no esquema teórico de percepção da estruturação do círculo do atraso regional visto sob o prisma da capacidade de poupança, investimento, dinâmica de mercado e socorro imediato à camada de trabalhadores mais empobrecida. (...) No plano material, a diminuição da pobreza absoluta e, no plano simbólico, a aderência à ideologia de que é possível superar a desigualdade por meio da expansão do capitalismo e da coalizão com as elites. (...) No plano objetivo, significa ampliaçáo do mercado interno com a expansão do consumo de massas, ambiente empresarial adequado às relaçóes de terceirização produtiva e naturalização da precarização das relações de trabalho. (...) Essas açôes não desconcentram renda (...). Os maiores aportes (cerca de 40\%) foram para as grandes empresas,

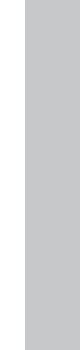

\section{政}


seguido pelas médias (18,9\%); ficando a pequena empresa e as cooperativas/associaçôes, somadas, na faixa dos 40\%. [...] ao levar investimento de ponta - ao estilo dos interesses do BNDES e dos fundos de pensão - para essas localidades carrega junto aquelas contradiçōes da acumulação, invariavelmente sustentada pela precarização do trabalho, pilhagem do meio ambiente, concentração fundiária e de renda. (MAGALHĀES et al, 2010). Um modo conservador e periférico da elite local participar das mudanças recentes do capitalismo, repondo as disparidades sociorregionais. (BARBOSA, 2012, p. 40-48).

Como síntese, constitui-se uma nação que ocupa o posto entre as dez maiores economias do mundo com o contingente de $1 \%$ mais rico da população ganhando quase cem vezes mais que os $10 \%$ mais pobres. Tal desigualdade continua possuindo um forte corte regional, o que faz, por exemplo, do Nordeste brasileiro concentrar cerca de $30 \%$ da população nacional e mais da metade da pobreza no país. (PNUD, 2013). Esse contexto torna-se mais agravante diante da implementação de uma violenta agenda de privatizaçóes no último ano, expondo o esgotamento do padrão de crescimento econômico, a reorganização das forças mais conservadoras, antidemocráticas e antipopulares, da sociedade e dos segmentos deliberadamente comprometidos com a ortodoxia neoliberal e desgostosos com os mínimos promovidos aos segmentos populares pela política conciliatória dos governos capitaneados pelo PT. Eis mais um episódio da nossa "restauração conservadora". (GRAMSCI, 2002).

Esse contexto tem sido propício para um rápido desencadeamento de um conjunto de açôes por parte do Estado demandadas para suprir as necessidades do atual ciclo de acumulaçáo do capital, priorizando outras vias de expropriação e intensificação de exploração do trabalho com a imposição de uma agenda mais intensiva de restrição de direitos sociais, mais precisamente trabalhistas, e de maior precarização com o incentivo às terceirizaçóes. Isto mediante 
o recrudescimento de mecanismos de controle, criminalização e punição das classes populares, expressando o quanto ainda é presente a "ideologia do colonialismo". (SODRÉ, 1984).

\section{O DESigual E COMbinado NA CONFIGURAÇÃo REgional do BRASIL}

Diante desse quadro, é impossível não se perguntar sobre os motivos que levaram a um movimento tão brusco de retirada de direitos, expressando um verdadeiro Estado de exceção na realidade mais recente do país, com maior notoriedade desde o ano passado. É certo que as repercussóes desse processo na "questão regional" são desastrosas, adensando rapidamente os efeitos dessa questão como resultado da capacidade de recomposiçáo capitalista em cada ciclo de acumulaçáo.

Voltando ao objetivo do presente texto, o que explica as inflexóes da questão social no Nordeste nos anos 2000? Ousamos aqui apresentar alguns sinais para que as respostas a tais questionamentos possam ser maturadas.

Antes de tudo, é certo que os anos 2000 compóe um período mundialmente mais favorável a expansão capitalista e ao desenrolar de medidas anticíclicas, porém com tempo cada vez menor de permanência. Para que isso ocorresse produzindo um impacto mais rápido e significativo, além de uma maior dinamização na economia, é possível observar a prioridade dada às regióes mais pauperizadas por parte da frente de alianças que dirigiu os últimos governos, ampliando o espaço para a expansão capitalista nos diversos setores da sociedade e as condiçóes mais propícias de crescimento sem maiores perdas em termos de lucratividade dos principais setores empresariais.

Daí o destaque do Nordeste, região que historicamente cumpre um papel central na divisão regional do trabalho,

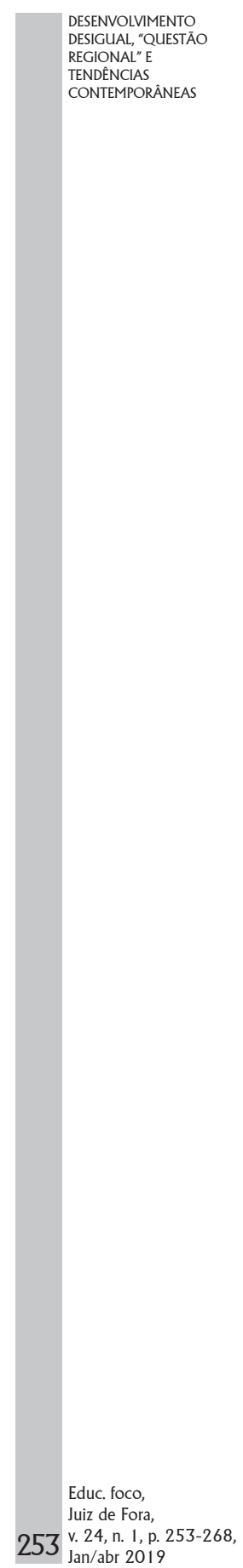


constituindo uma superpopulação relativa ${ }^{3}$ que tenciona o rebaixamento do preço da força de trabalho no país; com grande diferenciação salarial em relação à média nacional; menor índice de industrialização em comparaçáo a outras regiôes, implicando em taxas reduzidas de produtividade do trabalho e menor composição orgânica do capital; maior peso da pauperização absoluta e, portanto, de condiçóes de trabalho precárias; além da grande marca da questão agrária que retrai ainda mais o mercado interno e revela com maior clareza a relação orgânica entre o "moderno" e o "atraso" no capitalismo ${ }^{4}$ como desdobramento da lei do desenvolvimento desigual e combinado, uma importante chave de análise da realidade para entendermos que o "atraso" não é ausência de desenvolvimento capitalista. Sua combinação com o moderno pode causar um efeito em determinadas formaçóes sociais bastante distintivo, desbancando qualquer propensão a uma análise etapista e linear da história.

A desigualdade do ritmo, que é a lei mais geral do processos histórico, evidencia-se com maior vigor e complexidade nos destinos dos países atrasados. Sob o chicote das necessidades externas, a vida retardatária vê-se na contingência de avançar aos saltos. Desta lei universal da desigualdade dos ritmos decorre outra lei que, por falta de denominação apropriada,

3 "Todo trabalhador faz parte dela [superpopulação relativa] durante o tempo em que está desocupado parcial ou inteiramente. [...] ela possui continuamente três formas: líquida, latente e estagnada. [...] Quanto maior, finalmente, a camada lazarenta da classe trabalhadora e o exército industrial de reserva, tanto maior o pauperismo oficial. Essa é a lei absoluta geral da acumulação capitalista." (MARX, 1984, p. 206-209).

${ }^{4}$ Por levar em consideração a relação orgânica entre o "atraso" e o "moderno", o que, para nós, em outros termos, pode ser sintetizada na compreensão de "modernização conservadora" a partir de Florestan Fernandes (2006), optamos pelas aspas ao tratar desses termos como forma de atentar para o cuidado com possíveis equívocos que venham a recair no "dualismo estrutural". Corroboramos, assim, com as elaboraçóes de Francisco de Oliveira (2003). Já a concepção de "atraso" e sua relação com o moderno tem como base a leitura desenvolvida por Lênin (1982) e Trotstky (1977) a partir da análise da realidade do desenvolvimento capitalista na Rússia. 
chamaremos de lei do desenvolvimento combinado, que significa aproximaçáo das diversas etapas, combinação das fases diferenciadas, amálgama das formas arcaicas com as mais modernas. (TROTSKY, 1977, p. 24-25).

Tais fatores, vivos na sociedade brasileira, foram determinantes para a definição de prioridades dada à geração de postos de trabalho e investimentos em grandes projetos nos anos 2000. Isso, muito embora, contraditoriamente, também tenha implicado sobre um conjunto de resistências coletivas que expressam as diversas e antagônicas formas de enfrentamento à questão social na regiáo, a exemplo da forte e histórica presença de movimentos sociais, incluindo os de cunho sindical, de trabalhadores do campo. Esses aspectos, hipoteticamente, podem conduzir a uma explicação das inflexóes da questão social no Nordeste e a importância desse fenômeno para o último ciclo de desenvolvimento.

Diante desse quadro, é inegável que a expansão do capital e do mercado dinamiza com uma força muito maior e veloz a economia em regióes com as características que apontamos acima, onde o descompasso entre riqueza e pobreza é mais visível e profundo, o que tende, inicialmente, a beneficiar, em graus diferenciados, ambas as classes, representantes tanto do capital como do trabalho, atendendo aos seus diferentes interesses e necessidades. Isso, no entanto, é impossível sem o necessário intermédio do Estado que funciona, por um lado, como um subsidiário do capital, com os incentivos fiscais, uma política tributária regressiva e a apropriação do fundo público, e, por outro, como mecanismo de geração de novos postos de trabalho, subsidiário de programas assistenciais, ampliação da renda e do poder de consumo através do crédito, que também incrementa a acumulação capitalista, em especial o capital monetário, portador de juros, "mercadoria de excelência" do capitalismo nos nossos dias.

Para não esquecermos o nosso fio condutor expresso no movimento paradoxal, dialético, da realidade, é preciso

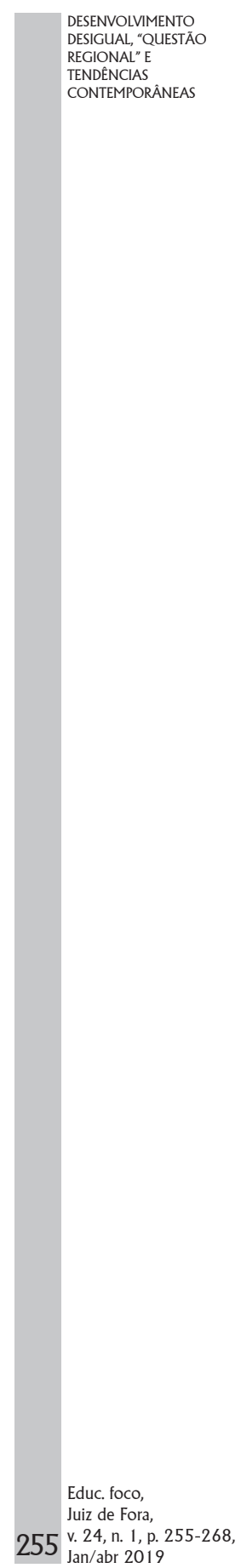


lembrar que, no enredo do capital, "as coisas são e não são", muito embora o que impere seja a lógica da mercadoria, da alienação e da barbárie, não da civilização. Porém, isso não nos tira as condiçóes possíveis de mudança e "desalienação". Afinal,

\begin{abstract}
(...) o desenvolvimento das forças produtivas provoca diretamente um crescimento das capacidades humanas, mas pode, ao mesmo tempo e no mesmo processo, sacrificar os indivíduos (classes inteiras) (...) - e aqui emerge plasticamente o problema da alienação - o desenvolvimento das capacidades humanas náo produz, obrigatoriamente, aquele da personalidade humana. (LUKÁCS, 2008, p. 161-162).
\end{abstract}

A história, longe de ser pré-determinada, nos mostra que "tudo que começa e deveria acabar de um jeito", pode acabar de outro. As contradiçóes da realidade, portanto, extrapolam os limites categóricos, conceituais e temporais que aqui priorizamos, já que o movimento de expansão e estagnação entre as regióes produz clivagens nas classes, disputas de interesses inter e intraclasse transcendendo qualquer dicotomia e polarização. Em outras palavras, a incorporação de trabalhadores e de regióes a dinâmica do capital produzem mudanças significativas e perceptíveis, porém, muitas vezes, ainda não absorvidas pelas classes em relação, em luta.

Nesse sentido, não podemos negar que a dinamização da economia a qual estamos nos referindo, mesmo com o grande desnível entre os ganhos do capital e aqueles voltados para o trabalho, pode interferir diretamente na prática das classes sociais e, portanto, nas condiçóes reais da luta de classes, muitas vezes até mais favoráveis para a luta dos trabalhadores diante de sua relativa recomposição em relação ao ciclo anterior do neoliberalismo no Brasil. Porém, esses "sinais" são para outros processos e possibilidades de pesquisa.

Retomando o caminho que priorizamos, podemos efetivamente perceber que nos anos 2000 houve no Brasil uma 
relativa alteração entre as formas combinadas de exploração da força de trabalho, destacando-se a pauperização relativa face ao período anterior (anos 1990); a conformação de um pêndulo entre acesso e precarização, viabilizando, por um lado, uma ampliação do consumo e mercado interno, uma diminuiçáo da pauperização absoluta, a recomposição relativa das classes trabalhadoras com o aumento dos postos de empregos formais, especialmente através de grandes obras no âmbito da construçáo civil, do agronegócio e demais polos da indústria de transformação. Por outro lado, intensificou a precarização do trabalho, sob a hegemonia de um neoliberalismo heterodoxo, interferindo na composiçáo interna da superpopulação relativa e na dinamização da economia local que, mediante a saturação das metrópoles e a busca de novos territórios de expansão do capital, tem conformado as "cidades médias" e outras regióes metropolitanas, especialmente no interior do Nordeste.

No fim das contas, estamos falando de um país que ainda possui uma população de 13,3 milhóes de analfabetos; um terço dos jovens de 18 a 24 anos sem concluir o ensino médio; e apenas 19\% da juventude tendo acesso ao ensino superior. (IBGE, 2012). Esse cenário torna-se mais alarmante quando associado ao número de trabalhadores na condição de ocupaçôes análogas ao trabalho escravo: das 1.550 pessoas resgatadas nessas condições em 2014, 39,3\% não tinham concluído o $5^{\circ}$ ano do ensino fundamental, 32,8\% eram analfabetos e $14,6 \%$ tinham do $6^{\circ}$ ao $9^{\circ}$ ano de escolarização incompletos. Já o déficit habitacional correspondia em 2012 a $8,53 \%$ da populaçáo, o que representa 5,24 milhóes de residências, adensando a violência e o conflito pelo acesso à terra que vem produzindo um alto número de assassinatos (36 no ano de 2014) e tentativas de assassinatos (56 no ano de 2014). (MEDEIROS, 2014, p. 26).

Essa realidade explicita uma condição inconteste: a política de conciliação de classes esbarra nos próprios limites capitalistas onde não há viabilidade do pleno emprego e, portanto, de agradar permanentemente a "dois senhores",

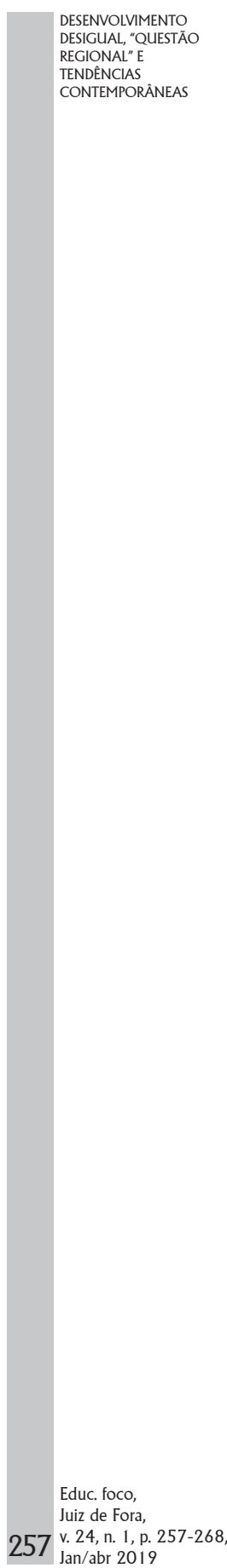


por isso as estratégias cada vez mais focalizadas na assistência como resposta as classes populares. Essas fronteiras operam sob a mediação da dependência estrutural, interferindo diretamente na configuração do Estado e na composição das classes sociais em luta. Portanto, os limites do último ciclo de desenvolvimento são também os limites de um Estado que combina, a um só tempo, oligarquia e financeirização. Aqueles que parecem ter descoberto o caminho da felicidade dentro do capitalismo sob a ilusão da riqueza para todos se esbarram no recrudescimento da política neoliberal. Não se trata fundamentalmente de vontade e opçáo política do grupo que se propóe a gerir o Estado capitalista, trata-se de uma determinação de ser do padrão de acumulação em questão.

Portanto, os ciclos de expansão capitalistas via "inclusão" e incentivo ao setor produtivo têm tempo de validade nas regióes de forma descompassada, tal como ocorreu no último período em terras brasileiras: enquanto houve, por exemplo, expansão da indústria automobilística foi possível a ampliação do crédito e de postos de trabalho. Já a expansão das empresas do agronegócio no Brasil - ao contrário da propagada em torno da geração de empregos, possível temporariamente -, vem sendo acompanhada pela informalidade, tendo apenas 36\% dos seus empregados com carteira assinada, além da grande ocorrência de trabalho análogo ao escravo. Fato este que tende a se agravar atualmente diante das modificaçôes na legislação trabalhista especialmente nas condiçóes do trabalhador do campo. ${ }^{5}$ Tal contexto representa a busca de outras vias para garantia de acumulação por parte dos capitalistas, mesmo que no ciclo anterior tenha sido possível um verdadeiro "salto qualitativo na conformação do grande capital interno" (BRETTAS, 2013), beneficiando determinadas fraçôes burguesas a se apropriarem ainda mais do trabalho necessário via exploração e expropriação de trabalhadores.

5 Cf. em: <https://www.brasildefato.com.br/2017/05/02/reforma-trabalhistarural-quer-acabar-ate-com-salario-do-trabalhador-do-campo/>. Acesso em: 04 mai. 2017. 
Ressaltamos que, mesmo com o incentivo dado ao setor produtivo, o caminho atualmente priorizado para dar prosseguimento ao processo de acumulação e valorizaçáo do capital é, por excelência, o processo de financeirização do capital e incremento do capital fictício. Por isso, o fortalecimento do agronegócio, através das commodities, junto ao favorecimento de grandes "grupos nacionais internacionalizados" durante os últimos governos, o que contribuiu na busca de legitimidade dos setores político-empresariais mais conservadores que encamparam o Golpe de Estado em curso no país.

As atuais medidas de austeridade e completa retração nos direitos sociais e políticos intensificam com maior violência a precarização, via empreendedorismo e terceirização, e, consequentemente, um diferenciado e aprofundado desenvolvimento desigual, interna e externamente. O movimento de concentração e centralização do capital toma renovada amplitude, reforçando a condição do Brasil de país agroexportador e dependente.

Os desdobramentos e efeitos dessa dinâmica atingem de forma particular regiôes como o Nordeste que, para nós, teve uma relevância para a duração do último ciclo de expansão do capital, desde o seu ascenso até o seu declínio, tal como foi no período desenvolvimentista do século XX, mesmo sob outras qualidades e proporçôes, funcionando como uma verdadeira "estratégia de hegemonia" do bloco no poder.

Em síntese, não é nosso propósito obscurecer as mudanças, mas analisá-las, na perspectiva da totalidade. Não temos dúvida que, de modo individual e temporário, muitos trabalhadores se sentiram beneficiados, mas, enquanto isso, o capital foi fortalecido total e permanentemente, o que pode ser demonstrado nos graúdos níveis de acumulação obtidos no mesmo período. Arriscamo-nos, portanto, a dizer que as mudanças não foram substanciais, uma vez que a forma de governar - malgrado as intençôes declaradas -, não rompe com as determinaçóes (neo)liberais. Na verdade, promove uma verdadeira "reforma do neoliberalismo". (MARA, 2016).

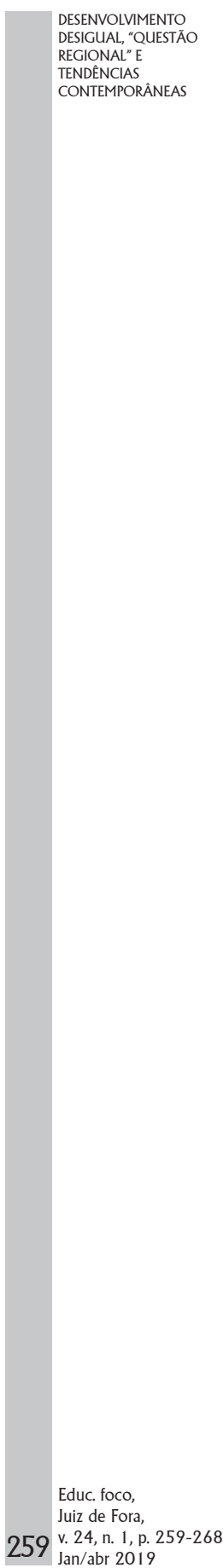


Tais determinaçôes, a nosso ver, estão expressas inclusive nos investimentos que, supostamente, pretenderam retirar o Nordeste do seu histórico “atraso". Pelos fatores já expostos, não havia riscos, mas tão somente ganhos, tanto econômicos quanto políticos. Talvez, o governo não previsse a temporalidade desses efeitos, do que, certamente, estavam cientes os capitalistas, que bem conhecem o tamanho de cada espaço econômico onde resolvem atuar, articulando fatores econômicos, sociais e culturais regionalmente dispostos e constituídos na formação social brasileira. O previsível esgotamento da capacidade do ciclo de crescimento presente na dinâmica do capitalismo contemporâneo, rapidamente reforçou a reproduçáo regional da lógica da dependência, a divisão internacional (e regional) do trabalho e, consequentemente, a confirmação da lei do desenvolvimento desigual e combinado.

Teria, então, o peso do descompasso entre ricos e pobres e do "atraso" sob o "moderno" no Nordeste favorecido o desenvolvimento capitalista dos anos 2000 com a atenção para o movimento de expansão do capital via industrialização, aumento real do salário-mínimo, ampliação do mercado interno, da capacidade de consumo, da formalização e produtividade do trabalho etc. na referida regiáo durante esse período? Por ora, a questáo é que tal movimento apresenta sinais de estagnaçáo desde o início da segunda década deste século, contribuindo para a profunda crise econômica e política em curso nos nossos dias.

Em outras palavras, a perspectiva pela qual interpretamos a realidade conduz a supor que as expressóes da questão social no Nordeste, tidas como progressistas no período estudado, estão fundadas na oportuna utilização do peso da "modernização conservadora" nessa região. O "atraso" (conjugado ao "moderno") teria parido um desenvolvimento na esteira de um movimento virtuoso de expansão de vida curta, o que não é nada surpreendente para a forma de ser (desigual e combinada) capitalista.

Portanto, apesar dos efeitos imediatos e de melhorias individuais, partimos do pressuposto de que a tentativa de 
governar mediante um modelo de conciliação de classes via pacto social permite apenas temporária e conjunturalmente alterar a "questão regional", ao ponto de, inclusive, repercutir no desenvolvimento do país, mas sem, substancialmente, reduzir a desigualdade social no Nordeste e no território nacional. Ao serem priorizados investimentos nessa regiáo, foram "matados dois coelhos com uma só cajadada": atendeuse ao fim capitalista e à população mais pobre. Isto, porém, nos limites de um modelo de conciliação.

Dessa forma, a contradição capital/trabalho pautou-se em fatores objetivos e subjetivos, constitutivos das medidas anticíclicas e da ideologia do desenvolvimento, necessárias para a garantia de hegemonia e para o alcance do seu fim. E conseguiu, pelo tempo em que houve espaço econômico para a expansáo do mercado, conforme a operante lei do valor. De repente, os ínfimos ganhos da população se esvaem ou, em outras palavras: "tudo que é sólido se desmancha no ar". Fica evidente a impossibilidade de fugir à lei do desenvolvimento desigual e combinado nos marcos do capitalismo.

Observamos que a realidade nordestina, ao se modernizar, mesmo que conservadoramente, torna-se cada vez mais partícipe da dinâmica de produção de desigualdades regionais numa mundialização que se regionaliza ou, em outras palavras, no "desenvolvimento do subdesenvolvimento". (GUNDER FRANK, 1973).

\section{CONSIDERAÇÓES FINAIS}

Entendemos que os aspectos elencados por nós sobre a realidade que aqui priorizamos reforçam e renovam, de forma mais complexa, uma característica constitutiva da lógica do capital: o desenvolvimento desigual e combinado, expresso na modernização conservadora, o que demonstra o quanto as mudanças transcorridas até hoje possuem muito mais elementos de permanência que de ruptura, sendo uma ou

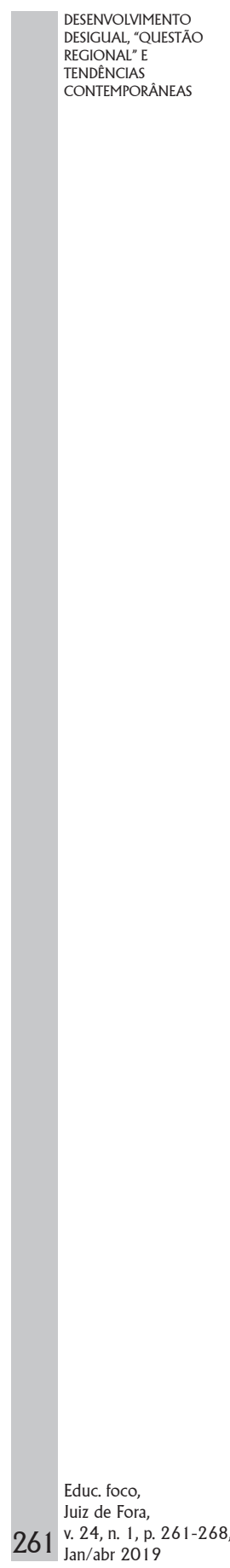


outra ampliada ou retraída a partir das contradiçóes presentes no desenvolvimento capitalista e na ação das classes sociais.

Portanto, um projeto de desenvolvimento pautado na conciliação dos interesses antagônicos, "apesar de avanços significativos e inegáveis nos indicadores sociais”, é incapaz de dar resposta às necessidades sociais e "alterar qualitativamente, a natureza da ordem oligárquica burguesa historicamente consolidada no Brasil", alimentada pela lógica capitalista de ser (ALVES, 2013, s/p). Ao contrário, para que se perdurasse esse projeto durante pouco mais de uma década, foi necessário o favorecimento de "grandes grupos nacionais internacionalizados", promovendo uma reacomodação no bloco de poder burguês, mas o fez com forte apoio popular, com uma política de valorização do salário mínimo e alguns programas sociais, mesmo que atravessados por uma série de restriçóes e condicionalidades, com impactos significativos especialmente para as regióes mais pobres. Para tal feito, foi fundamental a manutenção das altas taxas de juros junto à concessão de créditos a juros subsidiados, beneficiando também o capital portador de juros. Esse "jogo de cintura" não deixou de promover insatisfaçóes por todos os lados. (BRETTAS, 2013).

Tudo isso nos diz que há possibilidades históricas para contratendências, para uma súbita melhoria nos índices de crescimento econômico, combinada a uma reorganização dos mecanismos de exploração da força de trabalho com maior presença (em relaçáo a outros períodos históricos) da produtividade do trabalho e da pauperização relativa, mediante alteraçóes na composição interna da superpopulação relativa, em países e regióes específicas - o que, para nós, foi materializado na realidade brasileira da última década. Contudo, contraditoriamente, é o próprio desenvolvimento desigual entre as regióes um dos aspectos centrais para a conformação dessas contratendências, permitindo o crescimento econômico de algumas regióes e a estagnação de outras, constituindo constantemente um "exército industrial 
de reserva" que tenciona o rebaixamento do valor da força de trabalho. Essas mudanças, não sendo de caráter estrutural, (sobre)vivem em meio a constantes crises que, no entanto, sob a atuaçáo das classes, podem abrir fendas na hegemonia capitalista, acirrando a contradição entre as forças produtivas da sociedade e as relaçóes sociais.

Dessa forma, essa dinâmica é impulsionada não apenas pelos condicionantes e determinantes econômicos, mas, fundamentalmente, pelas circunstâncias e desdobramentos no âmbito político que póem em outro patamar a luta de classes. Esta, sendo universal é também regionalizada. (HARVEY, 2013).

É nesse contexto que se insere nos últimos anos o Nordeste brasileiro no "movimento mundial articulador de territórios", na mundialização que se regionaliza. Regiâo em que é possível constatar a presença de novos vetores de expansão econômica, porém mantém taxas que revelam desigualdades sociais ainda superiores aos índices nacionais. Afinal, "dada a própria natureza do capitalismo, esse processo de transformação não pode ocorrer de outro modo senáo em meio a uma série de desigualdades e desproporçóes: aos períodos de prosperidade sucedem os de crise, o desenvolvimento de um ramo industrial provoca o declínio de outro, o progresso da agricultura afeta aspectos da economia rural que variam segundo as regióes" (LÊNIN, 1982, p. 373-374).

Vale ressaltar, inclusive, as desigualdades históricas e continuamente vivas dentro da própria regiáo, do litoral ao sertão semiárido. "Essa combinação de crescimento econômico, desigualdade social e concentração de atividades dinâmicas em determinadas parcelas do território representa uma configuração socioespacial", recorrente no desenvolvimento capitalista em outras regióes do mundo. (PEREIRA JR., 2012, p. 225).

Enquanto isso, a crônica cotidiana composta por diversas trajetórias de vida daqueles que sofrem violentamente os efeitos da "questão regional" permanece presente, embora

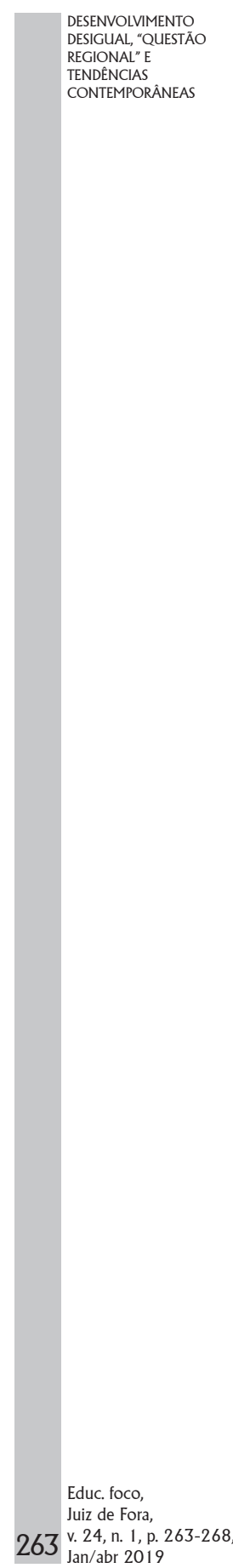


de forma reconfigurada, como marca intransponível nos marcos do desenvolvimento capitalista no Brasil e no mundo. Por fim, os meios para suprimir as barreiras espaciais e as distinçôes regionais, que limitam o padrão de acumulação em curso, envolvem a produção de "novas diferenciaçôes geográficas que criam novas barreiras espaciais a serem superadas. A organização geográfica do capitalismo internaliza as contradiçóes dentro da forma de valor. É isso que quer dizer o conceito do inevitável desenvolvimento desigual do capitalismo". (HARVEY, 2013, p. 528).

Todavia, é importante perceber que, ao contrário do quadro que o país vive hoje, as contradiçóes dos anos 2000 ofereceram melhores condiçóes de vida e trabalho para os segmentos mais pauperizados, que também são regionalizados. Resta saber, e a história dirá, se as consequências desse breve período poderão avolumar as possibilidades futuras de mudanças em um movimento de encontro ao avanço das forças conservadoras e reacionárias no atual cenário brasileiro. Isso certamente não dependerá apenas de uma região.

\section{REFERÊNCIAS}

ALVES, G. Neodesenvolvimentismo e precarização do trabalho no Brasil (parte I). 2013. Disponível em: <www. blogdaboitempo.com>. Acesso em: 02 mai. 2015.

APENAS 36\% dos empregados do agronegócio têm carteira assinada. Jornal Brasil de Fato, 2017. Disponível em: <https://www.brasildefato.com.br/2017/01/27/apenas-36dos-empregados-do-agronegocio-tem-carteira-assinada/ $>$. Acesso em: 04 mai. 2017.

ARAÚJO, T. B. de. Desenvolvimento regional brasileiro e políticas públicas federais no governo Lula. SADER, E. (Org.). 10 anos de governos pós-neoliberais no Brasil: Lula e Dilma. São Paulo: Boitempo; Rio de Janeiro: FLACSO Brasil, 2013. 
As mudanças no fluxo migratório brasileiro. São Paulo: Estadáo, 2011. Disponível em: http://jornalggn.com.br/ blog/luisnassif/as-mudancas-no-fluxo-migratorio-brasileiro>. Acesso em: 15 fev. 2016.

BARBOSA, R. N. de C. A Política Nacional de Desenvolvimento Regional: da "letra da lei" ao sentido do texto. In: Revista de Políticas Públicas. São Luís, MA: UFMA, v.16, n. 01, p. 37-50, 2012.

BRETTAS, T. Capital financeiro, fundo público e políticas sociais: uma análise do lugar do gasto social no governo Lula. (Tese) Departamento de Serviço Social da Universidade Federal do Rio de Janeiro. Rio de Janeiro, 2013.

CÂNDIDO, A. Grande Sertáo Veredas: Antônio Cândido sobre Guimarães Rosa. [mar. 2014]. Disponível em: <https:// www.youtube.com/watch?v=nn9YMb6S7VQ>. Acesso em: 12 mai. 2017.

DÓRIA, C. A. O Nordeste: "problema nacional" para a esquerda. In: MORAES, J. Q.;

ROIO, M. D. (Orgs.) História do Marxismo no Brasil. Vol.4. Campinas, SP: Ed. Unicamp, 2007.

FERNANDES, F. A Revoluçáo Burguesa no Brasil: ensaio de interpretação sociológica. 5.ed. São Paulo: Globo, 2006.

GRABOIS, I. Classes e fraçóes de classe no segundo Governo Dilma. 2014. Disponível em: <www.marxismo21. org >. Acesso em: 10 abr. 2015.

GRAMSCI, A. Cadernos do Cárcere. Vol.5. 3.ed. Rio de Janeiro: Civilização Brasileira, 2002.

GUNDER FRANK, A. Desenvolvimento do subdesenvolvimento latino-americano. In: Urbanizaçáo e desenvolvimento. Rio de Janeiro: Zahar editores, 1973. 
HARVEY, D. Os limites do Capital. São Paulo: Boitempo, 2013.

IBGE. Instituto Brasileiro de Geografia e Estatística. Pesquisa Nacional por Amostra de Domicílios. 2012. Disponível em: <http://www.ibge.gov.br/home/estatistica/pesquisas/ pesquisa_resultados.php?id_pesquisa=4>. Acesso em 12 nov. 2014.

IBGE: maior proporção de empresas de alto crescimento está no Norte e Nordeste. Brasília: EBC Agência Brasil, 2014. Disponível em: http://agenciabrasil.ebc.com.br/economia/ noticia/2014-12/emb-maior-proporcao-de-empresas-de-altocrescimento-esta-no-norte-e. Acesso em: 10 set. 2016.

IPEA. Instituto de Pesquisa Econômica e Aplicada. Brasil em desenvolvimento: estado, planejamento e políticas públicas. Brasília: IPEA, 2010. Disponível em:<http://www.ipea.gov. br/bd/publicacao_2010.html >. Acesso em: 29 jul. 2014.

LENIN, V. I. O desenvolvimento do capitalismo na Rússia. O processo de Formação do Mercado Interno para a Grande Indústria. São Paulo: Abril Cultural, 1982.

LUKÁCS, G. Socialismo e democratizaçáo. Escritos políticos 1956-1971. Rio de Janeiro: Editora UFRJ, 2008.

MARA, E. Pacto social e hegemonia burguesa: a reforma do neoliberalismo na Era Lula. (Tese) Departamento de Serviço Social da Universidade Federal de Pernambuco. Recife, 2016.

MARX, K. O Capital: crítica da economia política. Livro I, Tomo II. São Paulo: Abril Cultural, 1984.

MEDEIROS, L.S. de. Conflitos Fundiários e Violência no Campo. Conflitos do Campo. CPT Nacional: Brasil, 2014.

OLIVEIRA, F. de. Crítica a Razáo Dualista/O ornitorrinco. São Paulo: Boitempo, 2003. 
PEREIRA JUNIOR, E. Território e Economia Política: uma abordagem a partir do novo processo de industrialização no Ceará. São Paulo: Cultura Acadêmica, 2012.

PNUD. Programa das Naçóes Unidas para o Desenvolvimento. Atlas do desenvolvimento humano no Brasil. ONU, 2013. Disponível em:<http://www.onu.org.br/onu-atlas-brasil2013-mostra-reducao-de-disparidades-entre-norte-e-sul-nasultimas-duas-decadas/>. Acesso em: 26 jul. 2014.

POCHMANN, M. "Nós somos um país em que a desigualdade é nossa marca": Para o economista e presidente da Fundação Perseu Abramo, Márcio Pochmann, o Brasil está mais preparado para lidar com a desigualdade, mas certamente, está longe de superá-la. [nov. 2014]. Entrevistadora: Simone Freire. São Paulo: Jornal Brasil de Fato. Disponível em: <https://www.brasildefato.com.br/node/30631/>. Acesso em: 03 mai. 2017.

POCHMANN, M. Políticas públicas e situação social na primeira década do século XXI. In: SADER, E. (Org.). 10 anos de governos pós-neoliberais no Brasil: Lula e Dilma. São Paulo: Boitempo; Rio de Janeiro: FLACSO Brasil, 2013.

SODRÉ, N. W. A ideologia do colonialismo: seus reflexos no pensamento brasileiro. 3.ed. Petrópolis: Editora Vozes, 1984.

TRÊS em cada 10 resgatados de trabalho escravo em 2014 eram analfabetos. Brasília: EBC Agência Brasil, 2015. Disponível em: http://www.ebc.com.br/cidadania/2015/01/ tres-em-cada-10-resgatados-de-trabalho-escravo-em-2014eram-analfabetos. Acesso em: 03 nov. 2016.

TROTSKY, L. A história da Revolução Russa. 2.ed. Rio de Janeiro: Paz e Terra, 1977.

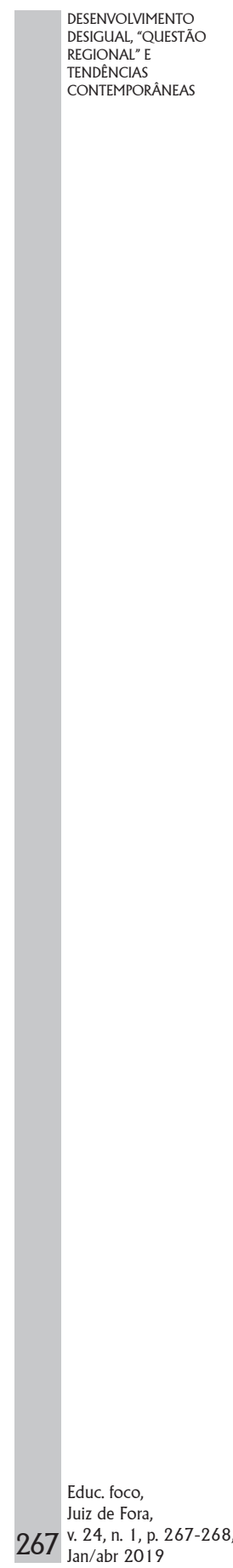


